\title{
El Cómic En La Clase De Ele: Las Actitudes De Los Estudiantes De Profesorado Y Algunas Repercusiones
}

\author{
Laurent-Fidèle Sossouvi (PhD) \\ Université d'Abomey-Calavi, Bénin
}

Doi: 10.19044/esj.2017.v13n28p282 URL:http://dx.doi.org/10.19044/esj.2017.v13n28p282

\begin{abstract}
Many researchers have considered comics as an excellent educational resource, pointing out to its advantages and its great educational potential. As a result, few authors have investigated the attitudes of students towards comics and they are rarely used as a teaching material in Benin in the learning of foreign languages. In this study, we aim to examine the attitudes of Beninese students of Spanish as a Foreign Language towards comic, as well as offer a reflection on some of the possibilities that can bring this teaching resource. In doing this, we analyze data from 25 participants which was obtained from a questionnaire, interviews, and tasks around the comic. Conclusions show that: (a) most participants showed a positive attitude towards comics and are highly motivated; (b) the use of comics contributed to improving their linguistic and intercultural communicative competences, as well as revitalized the learning of the target language. Finally, the paper concludes by pointing out the study's implications and limitations, and offering suggestions for future research opportunities.
\end{abstract}

Keywords: Attitude, didactic, learning foreign languages, creativity, comic

\section{Resumen}

Muchos investigadores han encontrado en el tebeo un excelente recurso didáctico, señalando sus ventajas y su potencial educativo. Teniendo en cuenta que pocos autores han investigado las actitudes de los usuarios hacia el tebeo y que se utiliza rara vez como material pedagógico en Benín en el aprendizaje de lenguas extranjeras, nos proponemos examinar las actitudes de los alumnos benineses de profesorado de español como lengua extranjera hacia el cómic, así como ofrecer una reflexión sobre algunas de las posibilidades que puede aportar. Para ello, se analizan datos, de 25 participantes, obtenidos de un cuestionario, entrevistas y tareas en torno al cómic. Se concluyó que: (a) los participantes, en su mayoría, mostraron una actitud positiva hacia el tebeo y están muy motivados; (b) la utilización del 
tebeo contribuyó a mejorar sus competencias lingüísticas, comunicativas e interculturales, así como revitalizar el aprendizaje de la lengua meta. Finalmente, se discuten las implicaciones de estos hallazgos.

Palabras-clave: Actitud, didáctica, aprendizaje de lenguas extranjeras, creatividad, cómic

\section{Introducción}

Este trabajo surge de nuestro interés por los cómics y la enseñanza de lenguas extranjeras. La intención es evaluar empíricamente las actitudes de los estudiantes para profesor de Español como Lengua Extranjera (ELE) hacia el cómic, con el fin de ofrecer algunas posibilidades de explotación didácticas. Los resultados de recientes investigaciones han demostrado que el uso del tebeo como herramienta didáctica en el aula de lenguas ha ofrecido una serie de ventajas que puede promover el proceso de enseñanzaaprendizaje e incluso contribuir al desarrollo sostenible de la competencia (por ejemplo, Djamel, 2007; Flores Acuña, 2008; Alonso, 2010; Guzmán López, 2011; Sossouvi, 2012; Castañeda San Cirilo, 2016, entre otros). Sin embargo, la integración de este documento auténtico en la enseñanza de Lenguas Extranjeras (LE) es aún modesta, o casi nula, especialmente en la enseñanza de ELE en Benín. Del mismo modo, pocos estudios han examinado las actitudes de los aprendientes hacia esta historieta. La mayoría de los estudios solo se han centrado en la integración de las Tecnologías de Información y Comunicación (TIC), Internet y sus recursos en el proceso de enseñanza-aprendizaje de lengua extranjera (por ejemplo, Lai, 2017; Son \& Windeatt, 2017). Así, en la literatura, los estudios sobre las actitudes de los discentes hacia las TIC, Internet abundan (por ejemplo, Slate, Manuel \& Brinson, 2002; Usum, 2003; Yang \& Chen, 2007; Barberá Cebolla \& Fuentes Agustí, 2012; Rial, Gómez, Braña \& Varela, 2014, entre otros).

Ahora bien, el uso del cómic, este medio de expresión universal, también podría abrir horizontes educativos más amplios, lo que puede permitir al educando adquirir más autonomía, más confianza en su aprendizaje, aprender de forma entretenida y sobre todo desarrollar sus habilidades lingüísticas, interculturales, sociales y pragmáticas y manejar la lengua meta como los hablantes nativos. Muchos autores (Anderson \& Krathwohl, 2001; Instituto Cervantes, 2006; Alonso, 2010; Sossouvi, 2012; Castañeda San Cirilo, 2016), se mostraron partidarios del uso del cómic en el aula de lenguas extranjeras.

Este estudio exploratorio podría reavivar el interés de los actores y profesionales de la enseñanza-aprendizaje de ELE por las bandas ilustradas. En las páginas que siguen, presentaremos en un primer lugar, la base teórica en la que trataremos de justificar el estudio y abordar el concepto de actitud. 
A continuación describiremos los distintos pasos llevados a cabo para la realización de este trabajo, presentando los informantes, los materiales y los procedimientos utilizados. Para finalizar, consideraremos los principales hallazgos que se obtienen de esta investigación, las interpretaciones $\mathrm{y}$ algunas pistas educativas.

\section{Algunas Consideraciones Previas}

Existe una distancia geográfica significativa y cultural entre Benín, España y los países hispanohablantes. De hecho, ningún país vecino inmediato del país africano tiene español como lengua oficial; por lo tanto, los estudiantes están aprendiendo en el contexto limitado y artificial del aula de clase, con muchas rupturas entre los cursos de lengua española y la dinámica interactiva de la vida cotidiana. El desarrollo de sus competencias sociolingüísticas y pragmáticas, en consecuencia se ve seriamente constreñido (Ellis, 1992; Tarone, 2000). Y así, se puede observar en sus producciones una mayor proporción de errores pragmáticos (Romero Trillo, 2002) y pueden permanecer "monoestilísticos" en la lengua meta (Gass, Mackey \& Pica, 1998; Dewaele \& Regan, 2002). Por consiguiente, la única competencia lingüística ya no es suficiente. Por otra parte, el aprendiente contemporáneo, incluyendo beninés, es un niño de la civilización de la imagen, ha abandonado el juego por la televisión y las redes sociales y se caracteriza por una delicada atención y falta de concentración. Tiene una buena memoria visual o fotográfica, que parece muy vital para consolidar el aprendizaje y la comprensión de la información en la preparación de un test, por ejemplo.

A pesar de la extraordinaria importancia adquirida en los últimos años por las TIC en las escuelas, la literatura científica reciente sugiere que todavía existe una proporción muy pequeña de docentes que en realidad las incorpora en sus prácticas docentes (Rogers, 2000; Schmid \& Schimmack, 2010). Esta utilización limitada puede ser causada, al menos en parte, por problemas en torno a la cualificación informática, por el analfabetismo digital o tecnológico, la falta de conocimientos informáticos de algunos docentes (sobre todo la tercera edad), su dificultad para aprender (de nuevo) a aprender a integrar las TIC en una perspectiva pedagógica (la tecnopedagogía), o la no percepción de su uso por parte de algunos. En efecto, muchos docentes son digitalmente analfabetos, o no tienen suficientes conocimientos digitales para los entornos laborales, docentes de hoy en día. Puede deberse también al acceso difícil a Internet en algunas zonas, principalmente las zonas rurales, o al alto precio de conectarse a Internet. Asimismo esta nueva cultura digital conlleva para muchos profesores importantes esfuerzos de formación, de adaptación y de desaprendizaje de muchas cosas, de la "bella época" que en realidad, ahora, ya no sirven. 
Ahora bien, desaprender resulta posiblemente mucho más delicado y complejo que aprender, ya que cuando uno se encuentra sumido en el círculo de una ola de rutinas y comportamientos que le han generado éxito, las modificaciones de comportamiento son mucho más difíciles. Lewis (2010: 9) abunda en la misma opinión, al subrayar que "New technologies open up possibilities unheard of in previous. But these technologies will have only limited impact if the pedagogy behind their application does not keep pace". Para Marton (1999), cada vez más docentes en todo el mundo están usando las TIC mucho más por la fascinación de la novedad que por intenciones puntuales de formación; y advierte de la tendencia a considerar estas tecnologías como una panacea para todos los males que sufre la enseñanza (de las lenguas extranjeras). Por otra parte, varios investigadores como Wisher \& Priest (1998) y Russell (1999) no constataron ninguna diferencia significativa entre el proceso educativo mediante la integración de las TIC y la enseñanza tradicional sin ellas. Otros autores como Mangelot (2016), ponen de relieve los principales beneficios que supone el uso pedagógico de las TIC, sin por ello infravalorar o rebatir sus limitaciones.

Del mismo modo, no faltan hoy autores como Leather (2003), Luis Banegas (2011), que constatan que la mayoría de los manuales escolares destinados a la enseñanza de las lenguas extranjeras faltan de realismo; quedan insípidos, fastidiosos, poco atractivos y a veces mentirosos (y llenos de disparates). Sossouvi (2014) llegó a las mismas conclusiones tras analizar la serie de libros de texto vigente en Benín.

En vista de lo anterior, se puede considerar que la diversificación de los recursos didácticos, de los dispositivos educativos, podría enmendar, por poco que sea, la situación. Los métodos y estilos de aprendizaje de LEs son múltiples e infinitos y se puede apoyar en una amplia variedad de medios o recursos educativos: textos, iconografía, imágenes fijas y en movimiento, multimedia. Y ahí radica la importancia del análisis de las actitudes de los alumnos-docentes de ELE hacia las bandas ilustradas, que van cobrando un mayor protagonismo en la cultura de la imagen en la que vivimos. El Consejo de Europa (2002: 93), con el Marco Común Europeo de Referencia (MCER) para las lenguas, Instituto Cervantes (2006) y Sossouvi (2012), entre otros, creen en la gran potencialidad de este medio narrativo, un recurso didáctico y pedagógico aprovechable para todo tipo de usuarios. En otras palabras, reconocen las ventajas y virtudes del uso del cómic, estas series de dibujos que cuentan una historia, en el aula. También creemos que estas bandas ilustradas, con su enorme potencialidad y riquezas, pueden posibilitar un aprendizaje eficaz de la lengua española, el desarrollo de competencias lingüísticas, culturales, fomentando al mismo tiempo un mejor nivel de autonomía del usuario en sus intercambios y potenciar las estrategias comunicativas en las clases. 
El aprendizaje de las lenguas extranjeras no puede ser concebido solo en términos cognitivos, hay que contar también con los factores afectivos y situacionales, que afectan positiva o negativamente este. Nosotros nos interesaremos en este trabajo por los factores afectivos, especialmente las actitudes y emociones ante el cómic de los estudiantes para profesor de ELE.

\section{Actitud}

La actitud ha sido objeto de varias investigaciones durante muchos años y a pesar de una extensa literatura sobre esta, se nota que la mayoría de las definiciones dadas por los investigadores (por ejemplo, Eagly \& Chaiken, 1993; Thomas \& Alaphilippe, 1993; Estrada Corona, 2012) es complementaria. No existe una definición unificada. Es un concepto clave para reflejar el modo de pensar, los comportamientos de un público o informantes. Si todo comienza por la educación, también todo empieza por una actitud. De hecho, el concepto de actitud por lo general se refiere a todas las valoraciones, las respuestas emocionales ante una comunidad, hechos o fenómenos sociales, los estímulos sociales o físicos, una persona, un objeto, hábitos o valores, etc. En síntesis, es el conjunto de disposiciones mentales, percepciones, juicios, sentencias que una persona expresa sobre cualquier elemento o fenómeno de su entorno. Informa sobre la predisposición o postura que el informante adopta frente al mismo.

Es un concepto muy amplio y de difícil definición, pero atreviéndonos a resumirlo en nuestro caso, la actitud es un estado mental o una disposición (o no) hacia la lectura del cómic. La mayoría de los investigadores tienen una vista unidimensional de la actitud (por ejemplo, Ajzen \& Fishbein, 1980; Petrof, 1999). Para estos autores, una persona evalúa un objeto, ya sea positiva o negativamente, es decir, tienen un sentimiento a favor o en contra de un objeto o fenómeno. En general, las apreciaciones o las valoraciones pueden ser positivas (comportamientos de aproximación, aceptación), negativas (comportamientos de rechazo, de evitación, hostilidad) o neutras (la persona no hace ninguna asociación positiva o negativa con la realidad circundante).

A pesar de que muchas veces las actitudes son difíciles de medir de una manera racional y ordenada, han sido y son siempre consideradas importantes en el proceso de aprendizaje de lenguas extranjeras. Muchos autores (por ejemplo, Potvin \& Paradis, 2000) demostraron que las actitudes de los discentes hacia un objeto, una persona, un fenómeno social, etc., determinan su comportamiento y su rendimiento tanto emocional como cognitivo. En consecuencia, por ejemplo, los aprendientes que poseen actitudes positivas hacia la lengua extranjera son los que mejores resultados alcanzan en su proceso de aprendizaje de la lengua, autonomía, fuerte motivación y la perseverancia. 


\section{El Estudio: Aspectos Metodológicos \\ Perfil de Los Participantes}

El presente estudio se realizó con 25 estudiantes universitarios de ELE matriculados en el segundo curso de Grado en la Escuela Universitaria de Formación del Profesorado de Porto-Novo durante el curso 2016-2017. En relación a su origen geográfico, procedían de los doce departamentos del país. Un $48 \%$ era mujeres $(\mathrm{N}=12)$ mientras que el $52 \%$ restante era hombres $(\mathrm{N}=13)$. Ninguno de ellos había viajado a España $\mathrm{o}$ a países hispanohablantes y su edad varía entre los 19 años y 35 años. El nivel de la lengua española es disforme, a pesar de que ellos habían empezado el aprendizaje en Quatrième, el tercer curso de Educación Secundaria. En consecuencia, llevaban unos siete años aprendiendo la lengua cervantina, por lo tanto, tienen un conocimiento intermedio o avanzado de español (B1 o B2 del MCER). Por otra parte, rara vez tienen la oportunidad de participar en una verdadera interacción con nativohablantes y fuera de la clase, todavía no poseen ninguna experiencia docente. Más de la mitad de la muestra es aficionada al noveno arte. En la Tabla 1 se observa la distribución de la muestra en función del sexo de los participantes.

Tabla 1. Distribución de la muestra por sexo

\begin{tabular}{|c|c|c|c|}
\hline Participantes & Mujeres & Hombres & Total \\
\hline 25 & 12 & 13 & 25 \\
\hline Porcentaje & $48 \%$ & $52 \%$ & $100 \%$ \\
\hline
\end{tabular}

\section{Instrumentos de Medida y Procedimientos}

En el presente trabajo se ha seguido una metodología mixta. La recogida de datos se llevó a cabo entre los meses de febrero y abril de 2017. Las actitudes hacia el tebeo se midieron mediante (a) la observación, (b) un cuestionario, (c) entrevistas, (d) una grabadora digital, (e) actividades en torno al cómic y (f) un cuaderno de apuntes en el que registramos los comentarios y observaciones eventuales.

Para este trabajo fue necesario diseñar un cuestionario ex profeso para conocer la percepción de nuestros participantes sobre el tebeo, ya que no hallamos en la literatura especializada cuestionarios o escalas validadas que se ajustaran a nuestros propósitos. El cuestionario se componía de quince preguntas acerca de su biografía, la profesión de sus padres, su repertorio lingüístico y las actitudes ante el cómic. Estas últimas se midieron a través de cuatro ítems, especialmente: ¿Lees tú cómics? ¿Por qué? ¿La lectura de cómics te ayuda en el proceso de aprendizaje de lenguas? ¿Por qué? Dicho cuestionario se cumplimentó por los participantes a principios del curso en febrero de 2017, durante el horario escolar, en un tiempo medio de quince (15) a treinta (30) minutos. 
Las entrevistas semiestructuradas con 17 de ellos también trataban sobre temas relacionados con el cómic: por ejemplo, ¿Por qué (no) te gustan los cómics? ¿Por qué te gusta leer cómic? ¿Qué tipo de cómic te gusta? Estas entrevistas nos permitieron establecer un contacto directo con los participantes, y tener la certeza de que no había ningún tipo de interferencia en sus respuestas. Duraban entre dos y diez minutos, y nos permitieron comprender mejor sus actitudes hacia los cómics o historietas.

Cada participante realizó seis actividades con tiras cómicas para reforzar el aprendizaje de la lengua española y evaluar la eficacia de estas series de viñetas que cuentan historietas como recursos didácticos. Nuestra verdadera meta era ayudarlos a mejorar, superar deficiencias en comprensión lectora, expresión oral y escrita; fomentar su deseo para intervenir activamente en tareas de innovación e investigación educativa, así como facilitarles algunas de las bases imprescindibles para iniciarse en este tipo de actividades. Las actividades se llevaron a cabo en el aula durante las horas lectivas. Los participantes contestaron a preguntas de selección múltiple con única respuesta en lo que se refiere a la comprensión global, asociaron diálogos a viñetas, completaron diálogos a partir de las informaciones dadas o identificaron las intenciones y sentimientos de los personajes, los registros de la lengua española.

A continuación presentamos algunas instrucciones de las actividades: A partir de la siguiente tira cómica, encuentra la historia poniendo las viñetas en orden. Imagina las palabras de cada viñeta. Describe los personajes de este cómic. Imagínate la situación. Elimina el texto de los bocadillos y crea una nueva historia. Aquí tenéis algunas viñetas de Mortadelo y Filemón desordenadas. Ordena el cómic para que la historia tenga sentido. ¿Alguna historia coincide con la original? etc. Después de dar instrucciones, pedimos a algunos participantes que lo explicaran al resto de la clase con sus palabras. Cabe señalar que cada actividad incluía al menos una docena de ítems y la forma de realización era individual o en tándem. Los tableros de historietas fueron sacados tanto de libros de texto (Salins \& Dupré La Tour, 1988, etc.) como de álbumes (viñetas de Tintín, Astérix y Obélix, Mortadelo y Filemón).

\section{Presentación e Interpretación de Los Resultados}

Solo expondremos en esta sección algunos resultados significativos, los que tienen que ver con sus actitudes generales hacia los cómics y las actividades. Por último, intentaremos interpretar y dar sentido a los resultados obtenidos y proponer algunas implicaciones. 


\section{Las Actitudes Expresadas}

Tabla 2. Actitudes de los participantes hacia los cómics

\begin{tabular}{|c|c|c|c|c|}
\hline ACTITUDES & MUJERES & HOMBRES & TOTAL & $\%$ \\
\hline Positivas & 06 & 11 & 17 & $68 \%$ \\
\hline Negativas & 01 & 00 & 01 & $04 \%$ \\
\hline Ambivalentes & 04 & 02 & 06 & $24 \%$ \\
\hline Neutras & 01 & 00 & 01 & $04 \%$ \\
\hline TOTAL & 12 & 13 & 25 & $100 \%$ \\
\hline
\end{tabular}

La Tabla 2 es un útil resumen de las principales actitudes identificadas. Se puede observar en la mencionada tabla cuatro tipos de actitudes.

\section{Actitudes Positivas}

Tal y como se observa en la Tabla 2, las actitudes de los participantes hacia esta herramienta de apoyo al aprendizaje son, en general, positivas. De hecho, el 68\% de los informantes ama y aprecia el cómic: "leer cómics, es muy bueno", "hay mucho humor y se puede reír mucho", "soy gran amante y lector de comic", "me apasiona". Esto podría explicarse tanto por el placer que la lectura del cómic procura como por su humor verbal y visual, esto es, el aspecto divertido y lúdico, incluso su papel como facilitador, dinamizador y motivador en el proceso de aprendizaje de lenguas. Otra explicación plausible sería el resultado de la asociación entre los cómics y los estímulos positivos, tales como experiencias felices, la identificación con los superhéroes del cómic, el juego concurrente de dibujos y textos, la lectura de esta herramienta desde la infancia, etc. Así, sus actitudes agradables resultan de la naturaleza hedónica, práctica de los cómics y la alegría durante las diversas lecturas. El cómic proporciona en cierta medida al usuario beneficios tanto utilitarios como hedónicos. Estas motivaciones hedónicas conllevan unas experiencias de placer, sensualidad, ilusión y desahogo (Dhar \& Wertenbroch, 2000).

Estos resultados muestran que los jóvenes estudiantes siguen mostrando entusiasmo por el noveno arte, y han reforzado nuestro punto de vista sobre la involucración de todas las generaciones en la aceptación del cómic. De igual manera, este hallazgo pone de relieve la función instrumental, utilitaria o pragmática de las actitudes. Además, sugiere que los estudiantes interesados por una herramienta, un objeto o una actividad lo valoran propiciamente. Este resultado corrobora los de Galvis (2010) cuyos informantes (el 87,5\%) manifestaron actitudes favorables hacia el bilingüismo inglés-español. Del mismo modo, según apuntan algunos investigadores como Marcos Llinas (2007), existen correlaciones significativas entre las actitudes positivas y una mayor motivación, el rendimiento lingüístico y la perseverancia en el aprendizaje de la lengua 
meta. Esta actitud positiva hacia el cómic refleja el entusiasmo, una tendencia favorable y un interés real por esta herramienta.

\section{Actitudes Negativas}

Solo una participante asumió una actitud global desfavorable hacia el cómic: "Nunca he leído un cómic, prefiero ver la televisión. Es para los niños y están llenos de estilo coloquial". Parece posible que este resultado se deba a la barrera económica, la edad de la participante, la falta de tiempo, el miedo de gastos innecesarios, la mentalidad retrógrada de algunos padres que ve la lectura de cómic como una lectura frívola y grosera, la influencia o repercusión de la gran variedad de actividades culturales, sociales y deportivas de hoy en día. Efectivamente, los estudiantes de hoy tienen una amplia gama de actividades deportivas, culturales, artísticas, etc., irresistible y accesible, que compite seriamente con el cómic.

La existencia continuada de la televisión digital, los nuevos discos Blu-ray 4K Ultra HD, Internet, redes sociales, en definitiva, los avances de las TIC, su presencia en la vida de las familias, en el entorno del aprendiente contemporáneo sin duda lo ayuda a leer menos u odiar este género textual. Además, como señalan algunos estudiosos como Osborne \& Collins (2000), Campbell (2001), entre otros, las actividades de lectura no son bien recibidas por los alumnos, son percibidas como un trabajo totalmente inútil y árido. Del mismo modo, la necesidad de diferenciarse de sus compañeros, por ser única, también puede explicar esta actitud de rechazo. Es una especie de protesta por la similitud con el fin de restaurar la autoestima. Estos resultados coinciden con los observados por otros expertos (Galvis, 2010; Boscán, Bohórquez, Hernández \& Medina, 2011; Sossouvi, 2012), cuyos informantes manifestaron también actitudes negativas.

\section{Actitudes Ambivalentes}

Tanto hombres como mujeres exhibieron un componente afectivo ambivalente hacia el cómic: "Me gusta el cómic pero me gusta cada vez menos, no me gusta", "sí y no". Globalmente, la aversión se expresa por algunas falsas creencias acerca del comic tales como la violencia, "es una lectura frívola", "es para niños"; mientras que la actitud favorable se correlaciona con beneficios tanto utilitarios como hedónicos, tales como los aspectos divertido y estético del cómic. Este hallazgo sugiere que se puede encontrar en un mismo individuo dos tipos de actitudes opuestas, actitudes entrelazadas. Esta accesibilidad simultánea de los aspectos positivos y negativos del tebeo indica cierto grado de madurez; los informantes se enfrentan a la realidad de manera dialéctica y con un espíritu crítico. Es de suponer que tienen una preferencia por la coherencia, una tendencia a la necesidad de cognición (Cacioppo \& Petty, 1982) y el miedo a la 
aproximación. Es también probable que esta ambivalencia de actitud se deba a su personalidad, su educación o sus experiencias.

Resultados similares han sido obtenidos por Conner \& Sparks (2002), Armitage (2003) y Sossouvi (2012). Sin embargo, estos resultados contrastan con aquellos de ciertas teorías de actitudes (por ejemplo, Eagly \& Chaiken, 1993; Petrof, 1999) respecto a la estructura unidimensional de actitudes, es decir, negativo o positivo. Esta visión bicéfala de las actitudes no refleja adecuadamente las realidades actitudinales de la vida: la existencia simultánea de sentimientos positivo y negativo hacia el mismo objeto o actividad. Uno puede preguntarse si esta ambivalencia no esconde también una especie de neutralidad, moderación o indiferencia, además, puede que sea un conflicto entre aproximación y evitación.

\section{Actitudes Neutras}

Solo una participante tuvo una opinión neutral respecto a si le gusta o no le gusta el cómic: "Nunca he leído un comic, por eso, no tengo ninguna opinión". Esta actitud neutral podría explicarse por la influencia del contexto cultural, específicamente la influencia de los prejuicios de género, las diferencias con las que se educan a niñas y niños en Benín (la lectura de cómic es cosa de hombres). En efecto, en el país, el cómic ha sido tradicionalmente asociado al público infantil, al sexo masculino con una función puramente de entretenimiento o considerado una lectura fácil y carente de imaginación. En consecuencia, la participante adoptó una actitud objetiva, desapasionada, se siente indiferente frente al cómic. Por otra parte, esta neutralidad podría resultar del desinterés, de incertidumbre, ya que la participante no llegó a identificar sus sentimientos, a decidirse. Este hallazgo no apoya las conclusiones obtenidas en Petrof (1999): la inexistencia de la actitud neutral.

\section{A Propósito de las Actividades y Entrevistas}

Con respecto a las actividades, nos dimos cuenta de que los participantes eran muy imaginativos. Las historias reconstituidas eran lógicas y adaptadas al contexto. Captaron bien la trama general, la sutileza de la intriga. Estas actividades también suscitaron debates muy enriquecedores que nos permitieron poner de relieve algunos elementos de civilización española y revisar los tiempos verbales. Por ejemplo, las críticas se centraron en la belleza de las imágenes o viñetas, las moralejas de las historias, la credibilidad o la falta de credibilidad de los hechos relatados, incluso la discusión de diferentes finales posibles a los escenarios. Efectivamente, las imágenes suelen dar muchas informaciones y detalles.

El uso del cómic ha dinamizado las interacciones entre los estudiantes durante las sesiones, ha provocado en el estudiantado una actitud 
receptiva y el ambiente era más relajado. En comparación con su rendimiento habitual, prácticamente todos los participantes realizaron las actividades con las mejores prestaciones. Es de remarcar que los participantes que tenían actitudes positivas participaron mejor que los demás.

Estos resultados generalmente satisfactorios, subrayan la importancia del uso de materiales auténticos en la enseñanza de LEs. También sugieren que la imagen y el texto están en una relación complementaria, cumplen una función adicional y el cómic aparece más divertido que los manuales. En definitiva, el cómic constituye un material auténtico que posibilita trabajar las cinco destrezas (comprensión auditiva, comprensión lectora, interacción oral, expresión oral y expresión escrita), una herramienta para ampliar el conocimiento del mundo hispánico, una fuente de motivación, un recurso incentivador, expresivo y familiar para el estudiantado beninés.

\section{Algunas Implicaciones}

De lo anterior se deduce que la mayoría de los participantes está motivada y tiene actitudes positivas hacia el cómic. Por otra parte, este último ha desempeñado un papel de facilitador, ya que con el cómic hay mayor nivel de comprensión de las informaciones. Su interés por este documento auténtico y el placer de aprender con este son bazas innegables para la enseñanza de ELE en el país. También puede afectar a la intensidad y la sostenibilidad de su participación en situaciones de aprendizaje, la profundidad de la comprensión. El empleo del cómic en el aula puede permitir al usuario sentirse cómodo, trabajar de forma cooperativa, intercambiar conocimientos lingüísticos, culturales, sociales, etc. Por tanto, la integración del cómic en el proceso de enseñanza-aprendizaje de ELE podría mejorar e incluso optimizar sus competencias generales, lingüísticas, sociolingüísticas, pragmáticas, la variedad del discurso, incluso cultivar el placer de aprender y con ello la felicidad.

El tebeo contiene informaciones multimodales lingüísticas y no lingüísticas que pueden contribuir a reducir los costes de adquisición de la lengua meta, optimizar el proceso de enseñanza-aprendizaje. Como señalan Anderson \& Krathwohl (2001), las imágenes ayudan a los usuarios a recordar, comprender, analizar, aplicar, evaluar y crear. La variedad de temas puede promover el desarrollo de una variedad de patrones, guiones específicos del mundo hispánico, así como les permitirá optimizar los procesos de comprensión, apañarse mejor y vivir mejor en un entorno hispánico e, igualmente, estar expuestos a una amplia gama de registros orales y escritos. Eso les evitará que, por ejemplo, tengan posibles malentendidos culturales y de significación con hispanohablantes. De hecho, puede ser para ellos una verdadera inmersión en la cultura hispanófona, una 
manera para estar en contacto con la lengua en su autenticidad, comprender mejor algunos hechos sociales divergentes y el desarrollo de su creatividad.

Con el lenguaje y recursos expresivos del cómic (su estructura, es decir viñeta y secuencia, y sus componentes icónicos, literarios, narrativos), los aprendientes benineses pueden desarrollar, mejorar sus competencias léxicas, gramaticales, semánticas, ortográficas, incluso sus estrategias de comunicación, tales como sus habilidades de comunicación no verbal (que se descuida muy a menudo en el proceso de enseñanza- aprendizaje), dotando al discurso de mayor dinamismo, vivacidad y espontaneidad. El uso del tebeo (cf. trabajo colaborativo) puede enriquecer las relaciones sociales entre los aprendientes (Silva, Hurtado \& Tique, 2013). Se puede utilizar el cómic como manual de lectura de ELE, ya que existe una interacción recíproca entre el dibujo y el texto. De hecho, se podrían transformar los libros de texto, libros de actividades lingüísticas en historietas o novela gráfica, es decir diseñar libros de cómics a los estudiantes, especialmente, de nivel A1 o A2. Efectivamente, en la narración gráfica existe una especie de simbiosis entre imágenes y literatura, además fomenta la creatividad y la imaginación. Pero este manual en formato cómics se desarrollará en estrecha colaboración con los expertos españoles o hispanoamericanos. Con su estilo de conversación, este medio expresivo y complejo constituye, por ejemplo, una manera muy agradable de enseñar o entrar en contacto con las onomatopeyas, enseñar explícitamente las estructuras retóricas. También es un buen material para trabajar el español coloquial, las variedades socioculturales y los registros idiomáticos, el humor español o hispanófono e incluso abordar un tema complejo sin aburrir a los aprendientes. En otras palabras, el cómic prepara a los discentes para una comunicación auténtica y eficaz; les ayuda a disponer de un repertorio lingüístico, mayor y más amplio, heterogéneo y creativo que les sirva para potenciar y variar sus medios de interacción social. Leer un cómic es descubrir en cada momento algo nuevo y un buen cómic es a veces mejor que un largo discurso docente.

Esta herramienta de comunicación efectiva puede resultar útil para enseñar o aprender con buen humor, y más rápido. Para fomentar los debates en clase, se puede recurrir a viñetas hispánicas. Esto puede favorecer la lectura crítica, el análisis de algunos clichés sociales y patrones de conducta de los hispanohablantes. En resumen, el cómic, cuyo lenguaje es muy rico y original, puede ser el punto de partida de actividades tanto orales como escritas en el aula de ELE y LE.

Este tipo de medio de expresión universal puede ser una ayuda a la traducción y a la autonomía. Se puede utilizar para mostrar a los aprendientes, las diferencias significativas entre el español y el francés, incluso las lenguas nacionales, es decir, hacer un análisis contrastivo de la traducción del español al francés y viceversa. Este documento auténtico 
puede desencadenar la creatividad, fomentar y consolidar la autoestima. Los estudiantes pueden jugar, escenificar o poner en escena el cómic, inventar historias sobre situaciones propuestas por los dibujos, incluso crear su storyboard, relato digital, con Comic Life, etc. Como estamos en la era digital, se puede utilizar el cómic en línea como recurso didáctico (Onieva López, 2015) y aprovechar el Mobile Learning, la impresión en 3D o de ULTRA HD 4K, etc. Puede ayudar a romper la monotonía, la falta de realismo de los libros de texto académicos o desarrollar el pensamiento crítico. Puede acompañarlos dentro y fuera de la escuela y estar disponible por mucho tiempo y los aprendientes pueden conocer a los autores más representativos de este ámbito como Forges, Mingote, Peridis, El Perich, Ricardo y Nacho, Pérez Navarro o Sempere y Quino, entre otros. En definitiva, el cómic, excelente material motivador, excelente método nemotécnico para el aprendizaje, puede contribuir a fomentar las capacidades interpretativas de los discentes, despertar más el interés por el aprendizaje del ELE e investigar más sobre la lengua y culturas españolas.

\section{Conclusion}

En este trabajo se ha analizado las actitudes de los estudiantes para profesor de ELE con respecto al cómic, con el fin de hacer hincapié en la importancia del uso del cómic como recurso didáctico en el aula en el marco beninés. Para ello, no solo se utilizaron un cuestionario y entrevistas, sino también actividades didácticas a partir de cómics. Este estudio ha encontrado que la mayoría de los participantes poseen una actitud positiva hacia el cómic y que han captado mejor las actividades con esta herramienta educativa. De todos modos, el balance final es satisfactorio, tanto en términos de competencias lingüísticas, culturales como interculturales. Por otra parte, los resultados de esta investigación apoyan la idea de que la actitud no es solo una variable unidimensional, sino también multidimensional. Al mismo tiempo, aprovechamos la oportunidad para esbozar algunas reflexiones y propuestas.

Con todo, como hemos visto, hay razones poderosas y suficientes que justifican el uso del cómic, y sería absurdo ignorar esta inclinación de los discentes por el noveno arte. El cómic aparece notoriamente como una herramienta para acompañar el proceso de enseñanza-aprendizaje de ELE en Benín, un factor potenciador, motivador y de facilitación del mismo. Puede acercar al discente al uso efectivo de la lengua española y aportarle las herramientas imprescindibles para interactuar convenientemente en cualquier circunstancia. Por lo que puede hacerse un hueco en el calidoscopio de los medios y recursos didácticos en el aula. Sin embargo, su uso debe ser complementario a la intervención del profesor, los otros medios de comunicación más populares, tales como las TIC, las redes sociales, el cine; 
por no hablar de la realidad del trabajo individual que el estudiante debe hacer para apropiarse la lengua meta.

En investigaciones futuras, podría ser posible trabajar con una muestra más representativa, ampliar la investigación a los estudiantes benineses de inglés, alemán y analizar los resultados obtenidos según origen socioeducativo y socioprofesional de los padres.

\section{References:}

1. Ajzen, I. \& Fishbein, M. (1980). Understanding attitudes and predicting social behavior. New Jersey: Prentice-Hall.

2. Alonso, M. (2010). El cómic en la clase de ELE: una propuesta didáctica. Madrid: Universidad Antonio Nebrija.

3. Anderson, L. W. \& Krathwohl, D. R. (Eds.) (2001). Taxonomy for Learning, Teaching and Assessing: A Revision of Bloom's Taxonomy of Educational Objectives. New York: Longman.

4. Armitage, Ch. J. (2003). Beyond attitudinal ambivalence: Effect of belief homogeneity on attitude-intention-behavior relations. European Journal of Experimental Social Psychology, 33, pp. 551563.

5. Barberá Cebolla, J. P. \& Fuentes Agustí, M. (2012). Estudios de caso sobre las percepciones de los estudiantes en la inclusión de las TIC en un centro de educación secundaria. Profesorado. Revista de currículum y formación del profesorado, 16(3), pp. 286-305. Recuperado de http://www.ugr.es/local/recfpro/rev163COL4.pdf

6. Boscán, L. Fr., Bohórquez, H., Hernández, A. \& Medina, N. (2011). Actitud del estudiante de ingeniería hacia sus errores en el aprendizaje de la matemática. Telos, 13(3), pp. 371 - 396.

7. Cacioppo, J. T. \& Petty, R. E. (1982). The need for cognition. Journal of Personality and Social Psychology, 42, pp. 116-131.

8. Campbell, B. (2001). Pupils' perceptions of science education at primary and secondary school. En H. Behrendt, H. Dahncke, R. Duit, W. Gräber, M. Komorek, A. Kross, \& P. Reiska (Eds.), Research in Science Education - Past, Present and Future (pp. 125-130). Dordrecht: Kluwer Academic Publishers.

9. Castañeda San Cirilo, L. (2016). Las utilidades del cómic como recurso didáctico en las aulas actuales. PublicacionesDidacticas.com, 68, pp. 130-136. Recuperado de http://publicacionesdidacticas.com/hemeroteca/articulo/068045/articu lo-pdf.

10. Conner, M. \& Sparks, P. (2002). Ambivalence and attitudes. European Review of Social Psychology, 12, pp. 37-70. 
11. Consejo de Europa (2002). Marco común europeo de referencia para las lenguas: aprendizaje, enseñanza, evaluación. Madrid: Instituto Cervantes, Ministerio de Educación, Cultura y Deporte- Anaya.

12. Dewaele, J. M. \& Regan, V. (2002). Maîtriser la norme sociolinguistique en interlangue française: le cas de l'omission variable de "ne". Journal of French Language Studies, 12(2), pp. 123-148.

13. Dhar, R. \& Wertenbroch, Kl. (2000). Consumer choice between hedonic and utilitarian goods. Journal of Marketing Research, 37(1), pp. 60-71.

14. Djamel, B. (2007). La bande dessinée comme support didactique dans l'enseignement du FLE. Synergies Algérie, 1, pp. 235-240.

15. Eagly, A. H. \& Chaiken, Sh. (1993). The psychology of attitudes. Orlando/FL: Harcourt Brace Jovanovich College Publishers.

16. Ellis, R. (1992). Learning to communicate in the classroom: A study of two language learners' request. Studies in Second Language Acquisition, 14(1), pp. 1-23.

17. Estrada Corona, A. (2012). La actitud del individuo y su interacción con la sociedad. Entrevista con la Dra. María Teresa Esquivias Serrano. Revista Digital Universitaria, 13(7). Recuperado de http://www.revista.unam.mx/vol.13/num7/art75/cita.html

18. Flores Acuña, E. (2008). El cómic en la clase de italiano como segunda lengua: posibilidad de explotación. Didáctica (Lengua y Literatura), 20, pp. 89-116.

19. Galvis, C. (2010). Actitud hacia el bilingüismo inglés-español en estudiantes de secundaria norteamericanos. Revista Nebrija de Lingüistica Aplicada, 8(4), pp. 96-99.

20. Gass, S. M., Mackey, A. \& Pica, T. (1998). The Role of Input and Interaction in Second Language Acquisition Introduction to the Special Issue. The Modern Language Journal, 82(3), pp. 299-307.

21. Guzmán López, M. (2011). El cómic como recurso didáctico. Pedagogía Magna, 10, pp. 122-131. Recuperado de www.pedagogiamagna.com

22. Instituto Cervantes (2006). Plan Curricular del Instituto Cervantes (PCIC). Madrid: Biblioteca Nueva.

23. Lai, Ch. (2017). Autonomous Language Learning with Technology. Beyond The Classroom. Londres: Bloomsbury Academic.

24. Leather, S. (2003). Taboos and issues. ELT Journal, 57(2), pp. 205206.

25. Lewis, G. (2010). Bringing technology in the classroom. Oxford: Oxford University Press. 
26. Luis Banegas, D. (2011). Comment: Teaching more than English in secondary education. ELT Journal, 65(1), pp. 80-82.

27. Mangenot, F. (2016). Le numérique entre effets de mode et réelle innovation. En A. Potolia \& D. Jamborova Lemay (Coords), Analyse de Enseignement / apprentissage des langues et pratiques numériques émergentes (pp.1-14). Paris: Éditions des archives contemporaines.

28. Marcos-Llinas, M. (2007). Variables afectivas en la clase de lenguas extranjeras. Interlinguística, 17, pp. 676-678.

29. Marton, Ph. (Ed.) (1999). Les technologies de l'information et de la communication et leur avenir en éducation. Education et francophonie, 27(2). Recuperado de http://www.acelf.ca/c/revue/pdf/EF-27-2-WEB.pdf

30. Onieva López, J. L. (2015). El Quijote en el cómic. Propuestas didácticas a través de webs y aplicaciones online. Cauce, 38, pp. 143155.

31. Osborne, J. \& Collins, S. (2000). Pupils' and parents' views of the school science curriculum. Londres: Association for Science Education, Hatfield.

32. Petrof, J. V. (1999). Comportement du consommateur et marketing. Québec: Les Presses de l'Université Laval, Sainte-Foy.

33. Potvin, P. \& Paradis, L. (2000). Facteurs de réussite dès le début de l'éducation préscolaire et primaire. Québec: Sainte-Foy.

34. Rial, A., Gómez, P., Braña, T. \& Varela, J. (2014). Actitudes, percepciones y uso de Internet y las redes sociales entre los adolescentes de la comunidad gallega (España), Anales de Psicología, 30(2), pp. 642-655.

35. Rogers, D. L. (2000). A paradigm shift: Technology integration for higher education in the new millennium. Educational Technology Review, 13, pp. 19-27.

36. Romero Trillo, J. (2002). The pragmatic fossilization of discourse markers in non-native speakers of English. Journal of Pragmatics, 34(6), pp. 769-784.

37. Russell, Th. L. (1999). The no significant difference phenomenon. North Carolina: North Carolina State University.

38. Salins, G.-D. de \& Dupré La Tour, S. (1988). Exercices de grammaire perfectionnement. París: Hatier.

39. Schmid, E. C. \& Schimmack, E. (2010). First steps toward a model of interactive whiteboard training for language teachers. En M. Thomas \& E. C. Schmid (Eds.), Interactive whiteboards for education: Theory, research and practice (pp. 197-214). New York: IGI Global. 
40. Silva García, Y. M., Hurtado, S. L. \& Tique, J. P. (2013). El cómic como alternativa formativa en aulas de aceleración y conocimientos básicos del IED. Colegio Manuela Beltrán Sede B. Revista Infancia Imágenes, 12 (2), pp. 94-100.

41. Slate, J. R., Manuel, M. \& Brinson, K. (2002). The "Digital Divide": Hispanic college students' views of educational uses of the Internet. Assessment \& Evaluation in Higher Education, 27(1), pp. 75-93. DOI: 10.1080/02602930120105081

42. Son, J.-B. \& Windeatt, S. (2017). Language Teacher Education and Technology. Approaches and Practices. Londres: Bloomsbury Academic.

43. Sossouvi, L.-F. (2012). Les attitudes d'apprenants taiwanais de langue étrangère à l'égard de la bande dessinée et quelques implications. Linguistik online, 55(5). Recuperado de http://www.linguistik-online.de/55_12/sossouvi.html.

44. Sossouvi, L.-F. (2014). Actitudes y motivaciones de los estudiantes sinohablantes y francófonos de lenguas extranjeras: esbozo comparativo. Ikastorratza. e-Revista de Didáctica, 13. Recuperado de www.ehu.eus/ikastorratza/13_alea/sinohablantes.pdf

45. Tarone, E. (2000). Still wrestling with 'context' in interlanguage theory. Annual Review of Applied Linguistics, 20, pp. 182-198.

46. Thomas, R. \& Alaphilippe, D. (1993). Les attitudes. París: PUF.

47. Usun, S. (2003). Educational uses of the Internet in the World and Turkey: A comparative review. Turkish Online Journal of Distance Education, 4(3). Recuperado de http://tojde.anadolu.edu.tr/tojde11/articles/usun.htm

48. Wisher, R. A. \& Priest, A. N. (1998). Cost-effectiveness of audio teletraining for the US Army National Guard. The American Journal of Distance Education, 12(1), pp. 38-51.

49. Yang, Sh. Ch. \& Chen, Y.-J. (2007). Technology-enhanced language learning: A case study. Computers Human Behavior, 23(1), pp. 860879. 